\title{
Hombres, mujeres y niños
}

\author{
Men, women and children | Jason Reitman | 2014
}

Liliana Aguilar*

Asociación Mundial de Psicoanálisis

Recibido: 13 de junio 2016; aprobado: 15 de junio 2016

\begin{abstract}
Resumen
El presente trabajo aborda, a partir del largometraje Hombres, mujeres \& niños(Reitman, 2014), la cuestión de los lazos en la época, los cuales se han modificado, entre otras cosas, por la introducción en la vida cotidiana de los objetos tecnológicos. La autora escribe sobre lo que implica tanto para Freud como para Lacan "el sexo" e interroga los imperativos propios del tiempo de la "liberación sexual".
\end{abstract}

Palabras clave: sexo | pornografía | tecnología| lazos

Men, Women and children

\section{Abstract}

The author thinks human relations from the intervention of technology, based on what the film may teach us about the current time, sex and technology. These topics are addressed from the perspective of psychoanalysis, taking into account current ties and the relationship that each individual has with his body.

Keywords: Current time | Sex | Body | Technology

\section{Introducción}

Hombres, mujeres E niños (Reitman, 2014) es una película que propone muchas aristas para conversar. Plantea cuestiones como la época, el sexo, la relación con la pornografía y por sobretodas las cosas propone el dilema de las relaciones humanas, algo que de alguna manera está tratado en todas las películas, pero esta vez con la intervención de un elemento que se va a mantener constante a lo largo de todo el largometraje: la tecnología. Es decir, que trata el dilema de las relaciones humanas en la era de la tecnología, sobre cómo y hasta qué punto los objetos tecnológicos ocupan un lugar central en nuestra vida, la inciden, la modifican, la afectan. Cómo y hasta qué punto estos objetos intervienen en nuestros lazos con los otros. También, y quizás esto es una de las cuestiones que resulta más interesante para pensar, - es una pregunta que los psicoanalistas nos venimos haciendo desde hace un tiempo- cómo y hasta qué punto estos objetos tecnológicos intervienen en nuestro cuerpo y, más precisamente, en la relación siempre tan compleja que tenemos con nuestro cuerpo.

\section{Hacer de psicólogo}

Escribir sobre una película no se trata de contarla o de explicarla, como tampoco se trata de explicar una obra de arte. Y mucho menos de interpretarla. Al hacerlo le sacamos la fuerza interpelanteque puede tener una obra, en este caso una película. Ya lo advirtió Lacanexpresando que cuando hacemos eso, hacemos de psicólogos. El psicólogo, para Lacan, es quien tiene el vicio de darle sentido a todo, como la religión. Desde esta concepción, por tanto, el psicólogo y el religioso se equiparan: todo tiene un sentido y hay que interpretarlo.

Si bien el psicoanálisis nace a partir de esta idea de que todo podía tener un sentido oculto, y a esto Freud le llamó “inconsciente", rápidamente se enfrenta a la cuestión de que develar el supuesto sentido oculto, no cura. Y que a pesar de las interpretaciones más refinadas, hay algo que

\section{lilianaaguilar28@hotmail.com}


insiste y que va más allá, y eso es la repetición. Eso que Freud llamó "la compulsión a la repetición” y que Lacan retoma como uno de los conceptos fundamentales del psicoanálisis. Las personas pueden entender qué les pasa, pueden entender qué los hace sufrir, también pueden entender, inclusive, que eso que hacen les hace mal. Lo que no entienden es por qué lo siguen haciendo. Eso está más allá y fuera de cualquier sentido o, mejor dicho, no lo tiene. Todo el mundo reconoce el descubrimiento del inconsciente como el gran aporte del psicoanálisis, pero hay que decir que "el más allá del principio del placer", esa tesis freudiana que evidencia que no es precisamente el placer lo que buscamos y que nos permite darle cierta lógica al porqué repetimos eso que nos hace mal, esta tesis, es tanto o más contundente que el descubrimiento del inconsciente.

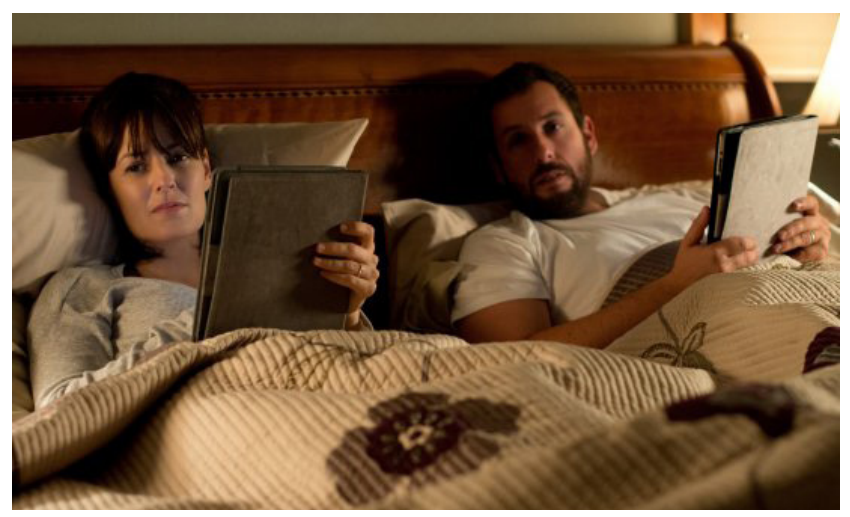

Entonces, si bien en un primer momento Freud entendió que había un sentido para todo, universal, que se llamaba el Edipo, o el Padre(como decimos los psicoanalistas), rápidamente se enfrentó también a la constatación de que el Edipo no alcanzaba a explicar algunas cosas, como por ejemplo ¿qué quiere una mujer? La primera respuesta que Freud le da a esta pregunta es en términos edípicos. Una mujer quiere el falo y porque quiere el falo envidia el pene. Y porque quiere el falo va a buscar un hijo. Desde esa perspectiva, esa es una respuesta al enigma de lo femenino. Pero rápidamente las pacientes de Freud le hicieron saber que su deseo, su goce, no se reducía al falo. Entonces, allí Freud se plantea la famosa pregunta que todos conocemos: ¿Qué quiere una mujer? De alguna manera, Freud planteó un más allá del sentido, un más allá del Edipo al introducir esta pregunta que si bien la reduce a las mujeres, luego Lacan la generaliza a lo femenino. Y lo femenino, podríamos decir, al menos esta es una de las maneras de definir lo femenino, es lo que está más allá del falo. Es eso que en cada quien, sea hombre o mujer, no se reduce a ser explicado con el Edipo, es eso que en cada quien no puede ser explicado con el falo.

\section{El detalle}

Entonces, ¿cómo hacemos para ir más allá del cuento que nos transmiten las películas, cómo hacemos para ir más allá del sentido?

Hacemos como cuando escuchamos un paciente, cuando escuchamos alguien que nos viene a ver porque sufre, o porque no sabe lo que pasa. Para no perdernos en el sentido, en el cuento, porque sabemos que esa vía no es la que orienta, entonces, para que no suceda eso, estamos atentos a los detalles, sobretodo esos detalles nimios que interrumpen el sentido. Entendemos que justamente allí, en ese detalle tenemos que detenernos. Por ejemplo, algo tan sutil y tan común como un lapsus que de pronto rompe el sentido de lo que alguien viene diciendo, o un tartamudeo que aparece en un determinado momento, o una tos que no deja seguir hablando justo cuando se estaba por decir algo, o un llanto que irrumpe cuando menos se lo espera, o una palabra que de pronto toma un relieve: por ejemplo, "el apañado" en un caso que recuerdo. Había dicho eso al pasar mientras contaba una historia, y el hecho es que hoy después de algún tiempo ni él ni yo nos acordamos de eso que contaba aquel día pero lo que ha quedado como brújula fue el "apañado". Porque el significante nombra, ubica, toca, su posición subjetiva, algo de su modo de gozar, de su modo de relacionarse con los otros.

El psicoanálisis ha enseñado, que el pequeño detalle vale más que el todo. A diferencia de la idea popular que considera que en los detalles uno puede perderse, el psicoanálisis, y no solo éste, nos enseña que uno se pierde con más frecuencia en las visiones de conjunto, cuando se sobrevuela y que por el contrario, el detalle, puede eventualmente ordenar de otro modo del que las ordena el conjunto y el sentido.

Entonces, para realizar un trabajo sobre esta película, nos orientaremos por el detalle, para no caer en una inclinación que, a primera vista, la película puede tener. Esa inclinación es la que nos deslizaría a la idea, que goza de bastante prestigio en el sentido común, de que los males de nuestra época tienen que ver con la tecnología, es decir, que la tecnología sería la responsable de lo que nos pasa.

Es muy difícil hablar de estos temas, debatirlos sin caer en el sentido común que es, por estructura, defensivo. El sentido común es aquello que usamos para 
defendernos de lo nuevo, de lo que no conocemos, de lo que no entendemos, de lo que nos asusta. Suele caer en lo normativo, en lo moral.

La posición del psicoanálisis se orienta por el reverso del discurso que impera en cada época, el reverso del sentido común de cada época. Que la tecnología interviene nuestras vidas, no hay ninguna duda. Que aparecen síntomas nuevos que tienen que ver con el uso de la tecnología, tampoco cabe ninguna duda. Pero de allí a pensar que la tecnología es el problema, reduce y simplifica las cosas.

Por estas razones considero que es fundamental escribir sobre la película partiendo de un detalle. Pero sucede que, y esta sería mi segunda hipótesis, esta película está presentada de tal forma que no se presta en demasía a ser tomada por un detalle. Quiero decir que, de alguna manera, la película expone las cosas sin mucha posibilidad de doble lectura, sin muchas sutilezas, sin metáforas. Es como si dijera: "así son las cosas". No hay momentos sublimes o rupturas, hay por el contrario una cierta monotonía.

Y quizás, esto sea justamente un logro en la película y no un defecto. Roger Koza, en el primer encuentro de la edición 2016 del Ciclo de Cine y Psicoanálisis, planteó una cuestión interesante al criticar el film $\mathrm{La}$ chica Danesa (Hooper, 2015). El entendía que había un exceso de hermosura, es decir que en cierto modo la película había abusado de los códigos de la belleza y al hacerlo había caído en el estereotipo, y que justamente el cine que a él le parece bueno es el que trabaja sobre los estereotipos pero se distancia de ellos. De alguna manera, podríamos decir que esta película consiente a mostrar la vida cotidiana, así como realmente vivimos, con un cierto aplanamiento, con una cierta mortificación. No hay grandes historias para contar de lo cotidiano, porque lo cotidiano tiene ese automatón del "más de lo mismo". En este sentido, podemos decir que la forma en que está hecha la película y en que está presentada, esa metonimia de escenas que pasan sin pena ni gloria, logra por momentos, darnos un pantallazo bien realista de lo cotidiano, de esa cierta vacuidad que tiene lo de todos los días. Del otro lado de lo cotidiano, en el otro extremo, tenemos el acontecimiento, eso que de pronto irrumpe en la vida para recordarnos que estamos vivos. Esto, por el contrario no es del orden del automatón, sino del orden de latyché . Pasa algunas veces, cuando pasa. Es del orden de lo contingente, de lo azaroso, pero cuando sucede, algo nos pasa, acontece, algo cambia. Allí, solo allí, podemos hablar de un antes y un después.
Es verdad que la película intenta que en determinado momento algo pase y de pronto vemos la comprobación de la infidelidad, el intento del suicidio del joven incomprendido, las madres que de pronto se dan cuenta de lo que hacen con sus hijas y se arrepienten, en fin. Quizás en este punto, la película cae un poco más en los estereotipos.

Sin embargo hay un detalle, si es que puedo llamarlo así, del que no me percaté de entrada, como suele suceder con los detalles. Fue recién cuando vi otras películas del mismo director, Jason Reitman, como Juno (2007), Up in the air (Amor sin escalas, 2009), Gracias por fumar (2005), que me percaté de algo. Son películas que toman temas controvertidos, polémicos, en boga. Por ejemplo, Gracias por Fumar, se presenta en el año 2005, cuando el cigarrillo está por alcanzar el punto cúlmine de la demonización. Juno, dos años después, en el 2007, plantea el tema de una joven adolescente que queda embarazada, es decir, que lo que está por debajo es el debate sobre el aborto y la tan en boga educación sexual. Luego, en $U p$ in the air el tema de los solos y las solas que viven para trabajar y que están dispuestos a todo para responder al amo capitalista. Siguen algunas otras que dejo en el camino y llegamos al 2014 con esta película que va a tratar el impacto de la tecnología en la subjetividad de la época.

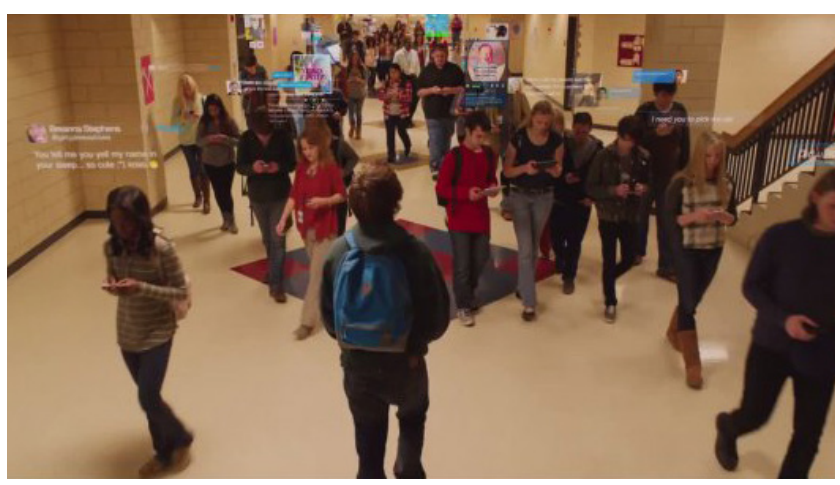

Y lo interesante no es solo el tema que tratan estas películas, temas que son muy sensibles a nuestra época, sino cómo los tratan. Siempre con un recurso satírico, con un cierto toque irónico, quizás allí está la sutileza que buscaba. Estas películas entran en el debate pero no nos dejan adivinar si están de un lado o están del otro. Si están a favor o están en contra. Son películas que no entran en un juicio de valor. Y este punto me resultó muy interesante porque tiene que ver con la posición ética de psicoanálisis.

Sin duda esta película, al mejor estilo Belleza Americana (Mendes, 2000), pinta una descarnada visión de la globalizada american way of life. Tenemos todos los 
estereotipos llevados a su máxima expresión: los padres caídos de su lugar de referencia o autoridad que tenían en otro tiempo: uno, Don, adicto a la pornografía y el otro, deprimido abandonado por su mujer. Tenemos también los dos estereotipos de las madres de esta época, la madre amiga que administra la página web de su hija para que llegue a ser la estrella que ella no pudo ser y tenemos también la madre controladora, Patricia, que odia Internet pero se vale de ella para satisfacer sus apetitos de control. Por el lado de los jóvenes tenemos la chica anoréxica, no podía faltar, tenemos a Tim, el deportista que abandona su vocación deportiva para dedicarse a jugar en red y también la que quiere ser famosa. En fin, todo el combo de los estereotipos de la época en que vivimos, una época intervenida por el inquietante avance de la tecnología que parece que va más rápido que la propia capacidad humana para adaptarse a ella y que nos enfrenta a algunas paradojas más que sorprendentes, como por ejemplo el hecho de que a medida que estamos más conectados, estamos más aislados en nuestros propios mundos virtuales.

Así como la película satiriza un poco la relación de una madre con una hija, íntimas amigas, que viven para y por una página web, satiriza también el extremo opuesto, esas madres que con el pretexto de cuidar a sus hijos de los peligros de Internet, se vuelven un peligro ellas mismas, como también vemos una pareja desencontrada, en donde cada uno se refugia en los interminables recursos que tiene la vida on-line para sobrellevar el desencuentro. También hay otra pareja de jóvenes que andan un poco solos y de pronto se encuentran. A partir de ese momento las redes se vuelven un modo de encontrarse, un modo de construir el lazo entre ellos, un modo de no quedarse solos.

En este sentido, hay una idea que es central en el psicoanálisis y es que el goce puede ser para lo mejor y para lo peor. Y por ende, todo aquello con lo que nos relacionamos que implica un goce, por supuesto, porque ninguna relación puede entenderse sin una circulación de goce, todo aquello con lo que nos relacionamos, sea una pareja, sea el trabajo, sea un libro, sea la pornografía, sea una droga, sea la comida, sea el teléfono celular, los juegos virtuales, sea lo que sea, puede ser para lo mejor y para lo peor. Dependerá, no tanto de los objetos en sí mismos, porque los objetos en sí mismos no son ni buenos ni malos, sino del arreglo o desarreglo que cada uno tenga con su propia manera de gozar. Desde esta perspectiva la tecnología puede ser para lo mejor y para lo peor.

\section{Y con el sexo ¿cómo andamos?}

¿Qué es el sexo para el psicoanálisis? Podríamos decir que para Freud, al reducir el dilema humano al Edipo, reduce todo a una cuestión sexual. Entonces todo circulará alrededor de lo sexual ya que tanto las mociones del inconsciente como las pulsiones son sexuales y el superyó es la instancia que intentará frenar los impulsos.

Para Lacan, en cambio, la dimensión del goce no se reduce a lo sexual. Incluso llega a decir que el goce como tal no es sexual. Lo sexual, en todo caso es una vía de tramitación de goce. Pero lo sexual, nunca alcanza a captar todo el goce, hay una parte del goce opaca. El goce, eso que no sabemos qué es pero sí sabemos que lo sentimos, porque lo experimentamos en el cuerpo, se tramita de muchas maneras y una de ellas es la sexualidad. Hay una parte del goce que se sexualiza, si se me permite decirlo así, que se localiza en un fetiche. Entonces se puede gozar sexualmente cada vez que alguien se encuentra con su fetiche. En esto tenía razón Freud, cuando hablo del niño como perverso polimorfo. Podíamos decir que la sexualidad humana es perversa polimorfa, es decir que cada quien tiene su fetichismo. Lo que pasa es que las épocas han intentado normativizar la sexualidad, cada una intentó hacer entrar esa perversión polimorfa de cada quien en alguna norma.

Entonces se instituyó una sexualidad normal, es decir adecuada a la norma y otra anormal, fuera de la norma.

El tema es que ahora, en la supuesta era de la liberación sexual, en donde paradójicamente nos encontramos cada vez más con personas un tanto desexualizadas y en la era de la liberación sexual, no nos libramos de las normas o de los mandatos. Resulta que ahora el mandato, tan cruel e inalcanzable como suelen ser los mandatos, es el imperativo a consumir. Entonces estamos obligados a consumir sexo. $\mathrm{Y}$ esto, lejos de liberarnos de aquellas normas que sofocaban la sexualidad, nos vuelve impotentes porque no estamos a la altura de semejante oferta de goce. Esto lo vemos en la película. Vemos cómo ellas tanto como ellos tienen sus dificultades para responder al encuentro sexual o incluso tienen sus dificultades para despertar el apetito sexual.

Desde esta perspectiva, "solo sexo", se puede leer como un sintagma liberador, en el sentido de que por fin ya no es un tabú querer tener encuentros sexuales, pero también se puede leer como un sintagma imperativo frente al que no vamos a poder estar a la altura. 


\section{Referencias}

Lacan, J. (1965 (2014]) “Homenaje a Marguerite Duras, por el arrobamiento de Lol V. Stein”, Otros escritos. Buenos Aires: Paidós. Lacan, J. (1972-1973 (1995] “Aun” en El seminario de Jaques Lacan. Libro 20. Buenos Aires: Paidós.

Miller, J.-A. (1989 (2010]) “Los divinos detalles” en Los cursos psicoanaliticos de Jacques-Alain Miller. Buenos Aires: Paidós. 